\title{
A CORPOREIDADE DE CATÓLICOS DA RENOVAÇÃO CARISMÁTI- CA: UMA ANÁLISE DAS TÉCNICAS CORPORAIS ${ }^{1}$
}

\author{
Letícia Rodrigues Teixeira e Silva \\ Universidade de Brasília, Brasília, DF, Brasil \\ Thaís Queiroz e Silva \\ Universidade de Brasília, Brasília, DF, Brasil \\ Dulce Filgueira de Almeida \\ Universidade de Brasília, Brasília, DF, Brasil
}

\begin{abstract}
Resumo
O objetivo do artigo é compreender a corporeidade de jovens católicos da Renovação Carismática, considerando as técnicas corporais em contextos rituais. O aporte teórico foi subsidiado por Mauss (2003), Csordas (2008), Maués (2000), Pereira (2009) e Sofiati (2009). A pesquisa, de inspiração etnográfica, utilizou como procedimentos a observação direta e entrevista empregadas junto aos jovens do Grupo de Oração Ágape da Paróquia Sagrada Família de Goiânia/GO/Brasil. Os resultados indicam que as técnicas corporais identificadas e interpretadas se mostram como forma de orar com o corpo. Conclui-se que cada técnica corporal tem significado singular (imitação prestigiosa), evidenciando a eficácia do contato com o sagrado, numa contínua relação entre corpo e espiritualidade.
\end{abstract}

Palavras-chave: Corporeidade. Técnicas corporais. Religião.

\section{EMBODIMENT FOR CATHOLICS OF THE CHARISMATIC RENEWAL MOVE- MENT: AN ANALYSIS BASED ON BODY TECHNIQUES}

\begin{abstract}
Our aim was to understand the embodiment of youth belonging to the Catholic Charismatic Renewal, considering the body techniques in ritual contexts. The theoretical contribution was based on Mauss (2003), Csordas (2008), Maués (2000), Pereira (2009) and Sofiati (2009). This study was ethnographically inspired and used direct observation and interviews with a Prayer Group called Agape, from the Sagrada Família Parish of Goiânia/GO/Brazil. The results indicate that the body techniques identified and interpreted are shown as a way of praying with the body. It is concluded that each body technique has a singular meaning (prestigious imitation), evidencing the effectiveness of the contact with the sacred, in a continuous relationship between body and spirituality.
\end{abstract}

Keywords: Embodiment. Body techniques. Religion.

\footnotetext{
${ }^{1} \mathrm{O}$ trabalho foi financiado pela Coordenação de Aperfeiçoamento de Pessoal de Nível Superior - CAPES; e quando apresentado no Third ISA Forum - Forum da Associação Internacional de Sociologia, em julho de 2016, em Viena/Áustria, contou com o apoio financeiro da Fundação de Empreendimentos Científicos e Tecnológico FINATEC e da Fundação Universidade de Brasília - FUB. 


\title{
LA CORPORALIDAD DE CATÓLICOS DE LA RENOVACIÓN CARISMÁTICO: UN ANÁLISIS DE TÉCNICAS CORPORALES
}

\begin{abstract}
Resumen
El objetivo es comprender la corporeidad de jóvenes católicos de la Renovación Carismática, considerando las técnicas corporales en contextos rituales. El aporte teórico fue subsidiado por Mauss (2003), Csordas (2008), Maués (2000), Pereira (2009) y Sofiati (2009). La investigación, de inspiración etnográfica, utilizó como procedimientos la observación directa y entrevista empleadas junto a los jóvenes del Grupo de Oración Ágape de la Paroquia Sagrada Familia de Goiânia/GO/Brasil. Los resultados indican que las técnicas corporales se muestran como forma de orar con el cuerpo. Se concluye que cada técnica corporal tiene un significado singular (imitación prestigiosa), evidenciando la eficacia del contacto con lo sagrado, en una continua relación entre cuerpo y espiritualidad.
\end{abstract}

Palabras clave: Corporalidad. Técnicas corporales. Religión.

\section{Introdução}

Este trabalho tem o intuito de compreender a corporeidade de jovens católicos da Renovação Carismática, manifestada por meio de técnicas corporais realizadas no grupo de oração Âgape ${ }^{2}$ da Paróquia da Sagrada Família, Goiânia/GO/Brasil. O objeto do estudo é, portanto, a corporeidade expressa por meio de um conjunto de técnicas corporais em um processo de "experienciamento", num contínuo entre corpo-espiritualidade (CSORDAS, 2008). Assim, no tempo em que transcorre o processo, que se perfaz por técnicas corporais, os jovens atuam tornando seus gestos atos que são, simultaneamente, tradicionais e eficazes (MAUSS, 2003).

Conforme Silva et al (2014), as práticas corporais podem ser entendidas por pesquisadores e campos de conhecimentos em diversas perspectivas, sendo necessário para tanto adjetivá-las. Concordando-se com os autores, esse artigo tem o desafio de inserir a interseção entre as práticas corporais e a religiosidade nos estudos da Educação Física, dando margem à construção de um olhar sobre as práticas corporais religiosas.

Desse modo, aliamo-nos ao que afirmam Mendes e Nobrega (2009), ao advogarem a favor da relação da Educação Física com explicações não-naturalizantes, concebendo seu objeto como um fenômeno cultural, que se materializa por meio do movimento humano. Nesse ínterim, é importante realçar que, ao trazermos a metodologia da corporeidade para refletir acerca de um fenômeno corporal que se evidencia no contexto religioso, estamos enveredando por um caminho novo e desafiador da Educação Física, também por nós compreendida como Educação do Corpo. Nesse caminho, outros autores, como Silva et al (2016), nos precederam, pois advogaram pela aplicação do paradigma da corporeidade (CSORDAS, 2008) aos estudos da Educação Física, com base em recortes como terapêuticas corporais, religiosidades e danças.

A pesquisa seguiu uma abordagem qualitativa, com orientação etnográfica, utilizandose da densa descrição (GEERTZ, 1989). O desenho metodológico está apresentado na sequência.

\footnotetext{
${ }^{2}$ Utilizaremos para nos reportar ao grupo de oração Ágape, de agora por diante, apenas o termo Ágape. Ágape significa amor, é um tipo de doação, um amor cristão, que não surge entre os homens, mas que é uma dádiva, um dom de Deus (QUADROS, 2011). É um grupo de oração composto por jovens e vinculado à Igreja Sagrada Família de Goiânia/Goiás/Brasil.
} 


\section{O desenho metodológico da pesquisa e grupo Ágape}

A fim de enveredar no universo católico carismático e construir uma análise da corporeidade de seus integrantes, escolhemos o grupo de oração Ágape, da Paróquia da Sagrada Família da cidade de Goiânia/GO. Esse grupo apresenta algumas peculiaridades no contexto local, a saber: goza de grande prestígio e reconhecimento social como agregador de jovens de classe média e alta; e contribui para a formação de casais em Cristo, o que dá ensejo ao estabelecimento de processos de socialização internos ao grupo. Uma das dificuldades para a realização de pesquisa em grupos religiosos, sobretudo católico, é o fato de que são normalmente fechados e dificultam o acesso de "estranhos". No entanto, uma das autoras fez parte do grupo durante longo período, facilitando deste modo sua inserção no universo pesquisado.

Dessa maneira, seguindo uma perspectiva etnográfica, o trabalho de campo foi realizado no período de sete meses e duas semanas, envolvendo o acompanhamento de distintas atividades promovidas pelo grupo, a saber: a intercessão; a missa de domingo à noite (acolhida); os encontros de sábado à noite; a adoração de iniciação dos servos; o retiro ${ }^{3}$ e a formação de servos, utilizando-se a observação direta, com registros em diário de campo e entrevista, que atenderam a um roteiro fixo.

Observando o grupo e atividades foi possível identificar que, ao todo, dele participavam 40 jovens, numa faixa etária entre 20 e 30 anos, de ambos os sexos e que tinham em comum o fato de aspirarem à condição de casados.

Para facilitar o trabalho de campo e posterior interpretação, categorizamos os participantes do Ágape em dois subgrupos, seguindo suas próprias autodenominações: servos, que são os coordenadores do grupo e foram identificados por nomes fictícios, Sandra, Paulo, Bárbara e Mateus. Eles atuam na coordenação com base nos dons recebidos do Espírito Santo e dividem as tarefas entre si e com os demais participantes. E os participantes, que foram selecionados conforme os seguintes critérios: (a) assiduidade; (b) nível de envolvimento e (c) divisão igualitária por sexo, já que uma das intervenções do grupo consiste em promover a união de jovens. Assim, foram observados e entrevistados 10 participantes, compondo, juntamente com os servos, os interlocutores da entrevista.

Após a realização do trabalho de campo, iniciamos o processo de cotejamento das informações (registros etnográficos) e interpretação, que se deu por meio do exercício antropológico num esforço textual e intertextual (CARDOSO DE OLIVEIRA, 1998). Para tanto, amparamo-nos em apropriações conceituais de Mauss (2003), Csordas (2008), Maués (2000), Pereira (2009) e Sofiati (2009), cotejando os registros do diário de campo e as entrevistas transcritas ${ }^{4}$, e então, selecionamos o conjunto de atividades, entendidas como rituais (PEIRANO, 2006), que foram acompanhas na pesquisa e serão a seguir interpretadas.

\section{Os rituais e as técnicas corporais no Ágape}

Atentando-se para a gama de atividades desenvolvidas pelo Ágape, podemos dizer que a intercessão; a missa de domingo à noite (acolhida); os encontros de sábado à noite; a adoração de iniciação dos servos; o retiro e a formação de servos constituem eventos que expressam um significado especial para o grupo de participantes. Esse significado especial e o caráter de peculiaridade na fala "nativa", isto é, dos próprios participantes, fazem-nos sugerir que eles sejam entendidos como rituais.

\footnotetext{
${ }^{3}$ Segundo a Renovação Carismática Católica Brasil (s/d), os retiros são encontros para oração semelhantes aos que ocorrem nos grupos de oração, no entanto eles ocorrem uma vez ao ano e durante um fim de semana visando aprofundar o conhecimento de renovação na fé.

${ }^{4}$ As informações obtidas, após transcritas e digitalizadas, foram submetidas à averiguação, por meio de uma leitura geral.
} 
Peirano (2006) advoga que os rituais são constituições que pertencem ao horizonte semântico do nativo, aquele que os vivencia. De acordo com a autora, talvez não seja sensato separar o que é ritual do que não é ritual, citando-a: "a concepção de que um evento é 'diferente', 'especial', 'peculiar' tem que ser nativa” (PEIRANO, 2006, p. 10). É precisamente essa apropriação teórica nativa que nos permite definir o conjunto de atividades (eventos) promovidos pelo Ágape, e que representam o desenvolvimento de seus trabalhos de oração, como rituais.

Desse modo, se um ritual é um tipo de evento que goza de um caráter de formalidade e de padrões constituídos, a formação dos servos é uma atividade que se reveste de caráter especial, apresentando aspectos que são simbólicos, estereotipados; além de possibilitar que as demais atividades aconteçam. A seguir descrevemos e analisamos alguns aspectos da formação dos servos.

Durante o ritual de formação dos servos, Paulo inicia o processo ritual solicitando
que todos se entregassem a Deus. As pessoas começaram a falar, faziam seus pedi-
dos; mas a voz de Paulo ficou, naquele momento, claramente destacada das demais.
Chamou-nos à atenção o fato de Sandra, uma das coordenadoras do grupo, que esta-
va com a face contraída a maior parte do tempo, emitir uma voz de choro nesse
momento, e ela começou a orar em línguas e sua oração parecia muito com o choro
de uma criança (Notas de campo, formação de servos, Goiânia, 02 de agosto de
2014).

Contrair alguns músculos da face semelhante a alguém que está prestes a chorar também é uma técnica corporal utilizada em momentos de oração. Em algumas das vezes o choro chega a ser efetivado com a excreção de lágrimas e, em casos mais raros, viram verdadeiros prantos. Segundo Pereira (2009), o choro é também uma técnica que corresponde à eficácia do contato com o sagrado.

Podemos afirmar com base na experiência do Ágape que a formação tem por objetivo favorecer a busca do servo por desenvolver um conjunto de habilidades que pressupõem a experiência do "dom" do Espírito Santo. Nessa experiência mística, que é individualmente construída, mas socialmente informada e reconhecida, o ator social passa por um processo de experimentação de sensações que o faz afirmar que se trata de uma experiência com Deus. Esse conjunto de sensações correspondem a tremores; visões; sonhos; vertigens, isto é, um conjunto de elementos fisiológicos que - combinados com aspectos psicológicos, sobretudo as emoções e a vontade de chorar, envoltos em uma comoção social, diante do grupo de servos e participantes - fazem com que o sujeito se entenda como eleito, possuidor do "dom" do Espírito Santo.

No primeiro dia em campo ${ }^{5}$, efetivamente o primeiro contato com todos os integrantes do Ágape, avistei Sandra e João, dois servos do ministério de intercessão.

Eles se encontravam no hall de entrada da catequese da Paróquia Sagrada Família. Cumprimentei-os, ajudei-os a se lembrarem de que eu era pesquisadora e que estaria ali para dar início ao meu trabalho de campo. Os demais servos iam chegando e se aglutinaram ao nosso redor. Todos me cumprimentaram com a mesma empolgação e alegria que cumprimentavam os demais. Mesmo aqueles que eu tenho certeza que não me conheciam, sempre estavam com um sorriso no rosto. Cordialmente, apertavam a minha mão ou davam um abraço, como se tivéssemos passado um longo tempo sem nos ver (Notas de campo, formação de servos, Goiânia, 26 de julho de 2014).

Se a primeira impressão é a que fica, como diz o dito popular, fui recebida e acolhida pelo Ágape como uma insider, poderíamos dizer nos referindo à compreensão já clássica de Elias (2000) com referência ao conceito de "estabelecidos" e "outsiders".

\footnotetext{
${ }^{5}$ Como dito anteriormente, a observação foi realizada no local da pesquisa, com a ciência dos participantes. As reuniões do grupo foram acompanhadas durante sete meses e duas semanas.
} 
A partir do episódio da recepção, recordamos Maués (2000), quando ele se reporta ao fato de que tais práticas constituem o primeiro toque corporal ${ }^{6}$ entre os carismáticos, sendo comum haver momentos de acolhida acalorados com aperto de mão, abraços. São palavras do autor:

[...] com apertos de mão e, muitas vezes, com abraços, mais ou menos formais mas, muitas vezes, bastante calorosos, dependendo da pessoa que recebe ou do grau de intimidade existente. Esse é o primeiro toque corporal, que frequentemente é acompanhado da fórmula: 'A paz de Cristo' ou 'A paz do Senhor'” (MAUÉS, 2000, p. 124).

O primeiro toque corporal também foi verificado em outros momentos. Bárbara, uma das servas, durante a missa de domingo à noite ${ }^{7}$, cumprimenta todos os que chegam à igreja, assim, mesmo aqueles que estavam tristes, quando veem um largo sorriso e desejos de boa noite e boa celebração, modificam imediatamente o semblante.

Um dos integrantes entrevistados ajuda-nos a compreender o sentido do momento da acolhida ao salientar que:

[...] é a hora que a gente vai mostrar que Deus é bom. Tipo assim, a pessoa chega ali do jeito que ela estiver. No momento que ela "tá" muito bem, ela pode ficar melhor. Ou ela pode tá mal, aí você vai dar um sorriso, um abraço... Você pode mostrar uma alegria no abraço, não falar nada, só falar assim "seja bem-vindo". Nisso a pessoa quebra a timidez. A gente utiliza muito isso, "né”? É a libertação da pessoa, se você tiver bem, se você tiver preparado, "num" aperto de mão você pode libertar a pessoa (PABLO, 2015).

Podemos entender esse momento de acolhida como um lugar privilegiado de interação social, que pressupõe um contato face-a-face, que atende às expectativas de si próprio e do outro, consistindo em comportamentos esperados. Diante desse processo de interação, há a construção de esquemas de representações no sentido tratado por Goffman (2002), posto que o próprio ator que inicia a ação dialógica, com a intenção de promover a acolhida, esforça-se para que todos acreditem que ele estava feliz com a presença de cada um dos fiéis durante a missa. Faz sentido afirmar que um indivíduo tende a influenciar pelas suas ações o modo com que os outros o verão, para isso o ator agirá de forma teatral para emitir uma impressão, a fim de obter dos observadores as respostas de seu interesse (GOFFMAN, 2002). Além disso, cabe um registro da prática da acolhida, que vai além da interação social e do reforço à espiritualidade. Sofiati (2009) evidencia em seus estudos sobre a Renovação Carismática Católica (RCC) que os católicos vivem um processo de perda de fiéis. Assim, os grupos vinculados à RCC tendem a encontrar meios que façam com que haja maior interesse e participação de pessoas da comunidade; sobretudo de jovens, por serem potenciais continuadores dos princípios religiosos do catolicismo.

Outras práticas corporais foram evidenciadas no grupo - destacamos o dar as mãos. Este gesto tem um peso simbólico na medida em que significa a unidade na interação, isto porque segurar as mãos, formando uma linha ou um círculo, pode expressar o sentido de que a força da oração está no senso do coletivo. Esses registros podem ser melhor evidenciados quando há a confluência de uma música que tem o propósito de fazer aflorar as emoções. Como quando cantaram " "Espírito enche a minha vida. Enche-me com teu poder' - a voz de Sandra se sobressaiu dizendo 'nos', no lugar do 'me' e anunciou 'pois de ti queremos ser' e todos assim cantavam" (Notas de campo, formação de servos, Goiânia, 02 de agosto de 2014). Havia ali um movimento sinestésico e de catarse coletiva, ao passo que a música emocionava

\footnotetext{
${ }^{6}$ As técnicas corporais estudadas estão marcadas no texto em itálico.

${ }^{7}$ A prática de interação social ocorreu em vários encontros durante o período que estivemos em campo.
} 
a cada um e a todos simultaneamente. O que foi ainda reforçado com a solicitação de Sandra dizendo "“agarra a mão do seu irmão e levanta o mais alto'. Todos assim fizeram e continuaram cantando. "As nossas mãos queremos levantar"" (Notas de campo, formação de servos, Goiânia, 02 de agosto de 2014). Esse movimento de catarse coletiva chegou ao ápice no momento em que todos estavam fazendo o movimento pendular (CSORDAS, 2008) de mãos dadas, indicando uma profunda conexão com o todo e consigo mesmo.

Pudemos observar na técnica dos movimentos pendulares que os participantes estavam apenas imitando o gesto de um dos servos, o que nos faz afirmar que o movimento pendular é uma técnica induzida por um servo, talvez como uma imitação prestigiosa (MAUSS, 2003). "É precisamente nessa noção de prestígio da pessoa que faz um ato ordenado, autorizado, provado em relação ao indivíduo imitador, que se verifica todo o elemento social" (MAUSS, 2003, p. 405). No caso, a noção de prestígio estaria relacionada à maior possibilidade de contato com Deus, o que pressupõe que houve sucesso na primeira ação, por conseguinte, outros participantes imitam os prestigiosos, gerando-se com isso o aspecto social da imitação.

Durante uma oração de efusão, um servo realizava a imposição de mãos em um participante, enquanto ambos oravam em línguas. Em um dado momento, pareceu-nos que o participante começou a ceder ao toque (ou pressão exercida) e balançar de um lado para o outro. Csordas (2008) afirma que para os carismáticos o poder de Deus se manifesta através de técnicas corporais chamadas de técnicas retóricas de empoderamento, pois o corpo é o meio mais concreto e imediato de persuadir as pessoas da realidade do poder divino. Nesse sentido, acreditamos que tais movimentos, ao serem realizados em um momento de oração ou com alguma música, têm o intuito de mostrar que o poder divino tomou conta da pessoa, independente do caminho (oração, música ou imposição de mãos) percorrido para chegar até ela.

Dando continuidade ao momento de efervescência, "Paulo recomendou a todos que colocassem as mãos no coração e fizessem uma oração de súplica, um pedido para si mesmo. Todos soltaram as mãos e acataram a sua recomendação" (Notas de campo, formação de servos, Goiânia, 02 de agosto de 2014). Esse gesto de colocar as mãos sobre o coração - tórax - é geralmente associado a uma leve inclinação da cabeça, mantendo-se os olhos fechados. Tal técnica acontece em momentos introspectivos.

Durante a oração em línguas, observou-se uma vasta gama de técnicas corporais, que de alguma forma refletem, para os carismáticos, a ação do poder de Deus. Uma observação em campo ajuda a ilustrar:

Na formação de servos, havia uma moça, Amanda (serva da intercessão), que estava com sua mão direita no coração, e com seu cotovelo esquerdo flexionado junto à cintura, ela não estava embalada pela canção, mas ao realizar suas orações movia sua mão (que estava com a palma voltada para cima) para cima e para baixo, em movimentos rápidos e intermitentes (Notas de campo, formação de servos, Goiânia, 26 de julho de 2014).

O curioso é que para orar não é necessário só movimentar a boca para produzir algum som, mas fazer algo a mais com o corpo, por exemplo, embalar-se ao som da música, contrair algum músculo da face, ou utilizar técnicas corporais repetitivas (que tem a característica de serem rápidas e intermitentes), como as de Amanda.

A oração em línguas pode ser interpretada como forma alternativa de mostrar que todos naquele ambiente continuavam em estado de oração. A glossolalia pentecostal é uma forma de elocução caracterizada pela falta de um componente semântico, pronunciando-se sílabas desconexas. Carrega um significado global como sendo uma forma inspirada de louvar a Deus, mas também pode ser utilizada como uma prece que roga por intervenção ou orientação divina. Contudo, entre os carismáticos, há distintos padrões sintético-fonológicos. Pode 
haver mais de uma "linguagem de oração" glossolálica, podendo elas serem usadas em diferentes situações e com diferentes intenções (CSORDAS, 2008).

A imposição da mão também foi notada como uma técnica inserida em alguns rituais do grupo, mencionamos:

Barbara, Isabela e Júlia (servas do ministério da acolhida) se ajoelharam. As pessoas em volta iniciaram a técnica da imposição de mãos, colocando as mãos no ombro ou na cabeça de cada uma delas e, quando isso não era possível, sobre o ombro da pessoa que tivesse o contato direto com a pessoa ajoelhada. Alguns rezavam com as suas palavras e outros em línguas. (Notas de campo, formação de servos, Goiânia, 02 de agosto de 2014).

Impor as mãos, para Maués (2000), é técnica corporal de relevo entre os carismáticos e, para Csordas (2008), é uma retórica de empoderamento. Ou seja, a pessoa que recebe a imposição das mãos se sente mais convencida que o poder de Deus chega não só pela oração que está recebendo, mas principalmente pelo toque.

No Ágape, as palmas apareceram com significados distintos no acompanhamento aos cânticos. De acordo com Maués "As palmas podem ocorrer em várias situações, inclusive durante a missa, em resposta a certos atos rituais ou palavras do sacerdote" (2000, p. 128). Nas reuniões com servos e participantes, as palmas apareciam estrategicamente na composição coreográfica. Na missa, as palmas eram elemento de interação, para as pessoas que não sabiam a coreografia durante os cânticos. Portanto, as palmas podem ser consideradas técnicas corporais importantes entre os carismáticos, atendendo a significados distintivos dependendo do ritual e do momento do rito.

Igualmente importante é a técnica de repousar no espírito. Foram momentos em que algumas pessoas, notadamente após a imposição de mãos de servos que possuíam o dom do Espírito Santo, perdiam momentaneamente os sentidos, desequilibrando-se ou mesmo caindo. No grupo, as pessoas só repousaram em momentos de orações profundas e, de certa forma, mais individuais, como adoração, momentos de cura interior e efusão (quando se pede que o Espírito Santo se manifeste em si próprio). O momento que descrevemos a seguir foi voltado para cura e ocorreu no ritual do retiro.

O pregador pediu para cantar a música Por hoje não. Enquanto cantavam, alguns servos faziam imposição de mãos em participantes, na maioria das vezes tocava-se no ombro e na cabeça. Quando tocadas, a maioria das pessoas chorava ou contraía a face simulando o início de um choro. Muitas pessoas que ainda não foram tocadas por alguns servos se embalavam ao tocar da música. Pude notar que uma pessoa, sob a imposição de mãos de Sandra, repousou. A pessoa estava com a face contraída, enquanto Sandra rezava por ela e também realizava movimentos pendulares leves para frente e para trás. A pessoa repousou caindo na diagonal para frente e para o lado, enquanto Sandra tentara amenizar a queda (Notas de campo, retiro, Aparecida de Goiânia, 29 de novembro de 2014).

O repouso no espírito constitui-se como uma "experiência marcada pela tomada de todo o corpo do sujeito pelo Espírito Santo - consequência simbólica e física, da entrega de si a Deus" (SOFIATI, 2009, p. 59). Trata-se de um momento especial da experiência religiosa, em que o Espírito rende o corpo humano de suas resistências de forma que a própria pessoa não tenha controle sobre o seu corpo e, por isso, acabe caindo ao solo.

Ao fim da oração o novo pregador foi convidado, e conduziu um momento de oração com ênfase na manifestação dos dons do Espírito Santo, em especial o 
dom das línguas e do repouso. Ele pediu para não ter medo e dirigiu um discurso, a fim de produzir a predisposição nos fiéis. Após realizar seu discurso, ele começou a cantar uma música, os músicos deram continuidade, eles e os servos circularam em meio aos participantes realizando a imposição de mãos e rezando por eles. O pregador interrompeu a música para ensinar a orar em línguas, ele disse assim "Repete comigo, aba Pai! Aba Pai! Aba Paizinho! Abaladoba. Adabadala. É assim mesmo, continua! Abadolabolalalalelele" (Notas de campo, retiro, Aparecida de Goiânia, 29 de novembro de 2014).

Essa forma de ensinar expondo um conjunto de técnicas, a fim de facilitar a eficácia do contato com o sagrado, lembra-nos mais uma vez da noção de imitação prestigiosa de Mauss (2003). Tudo o que se aprende é imitável e mesmo que seja uma imitação, ela possui reconhecimento social. É exatamente por isso que se propõe uma imitação de experiências místicas, como também foi evidenciado durante a formação dos servos, o repouso no espírito e em outros rituais do Ágape.

Ao pensar nessa questão de prestígio das técnicas corporais, podemos dizer também que por mais que as técnicas sejam encenadas, elas possuem um significado. Tal significado produz efeito no grupo, tornando-o mais coeso e unido ao seu sentimento de fé e é por isso que eles continuam orando com movimentos rápidos e intermitentes, em línguas e repousando no espírito, pois o conjunto de técnicas corporais empreendidas reforça o sentimento de coletividade, ao mesmo tempo em que é eficaz e se mantém de modo tradicional no grupo investigado.

\section{Considerações finais}

O trabalho teve a intenção de realizar a compreensão da corporeidade entre católicos carismáticos de um grupo de oração de Goiânia, o Ágape. Objetivou-se, por meio da pesquisa etnográfica, buscar o significado de um conjunto de práticas e técnicas corporalmente construídas, com a finalidade de interpretá-las no contexto dos rituais em que elas eram desenvolvidas. Procuramos apontar caminhos para a reflexão sobre as técnicas corporais de cunho religioso, oferecendo uma leitura a partir da corporeidade dos atores sociais nelas envolvidos. Sobretudo por se tratar de fenômenos que se manifestam na esfera religiosa, as técnicas corporais não se separam do momento de oração, e se colocam como oração realizada pelo e com o corpo.

Desse modo, nossa reflexão tentou superar a tradicional dicotomia entre sujeito e objeto, para direcionar uma reflexão que recupere os nexos entre os corpos e a divindade na dinâmica da experiência social vivida por meio das técnicas corporais. Buscar superar essa dicotomia, tão histórica e atual nos estudos da Educação Física biologizada, nos aproximou desse corpo-experiência, reprodutor de técnicas corporais ao mesmo tempo que provocador de subjetividades e fenômenos culturais complexos.

Identificamos as seguintes técnicas corporais: o primeiro toque corporal; o dar as mãos; os movimentos pendulares; a oração em línguas; as palmas e a técnica de repousar no espírito no grupo investigado. Essas técnicas são uma ação construída corporalmente, por meio de um conjunto de gestos, individualmente construídos, mas que se remetem a aspectos sociais que atendem a uma espécie de convencimento do outro a fim de influenciar a maneira como o outro atua. Assim, há a aproximação com o outro - interação social, e também há a aproximação com Deus, podendo haver libertação ou mudança na qualidade espiritual do acolhido.

As técnicas corporais se mostram como uma forma de se orar com o corpo, que requisita a busca pela transcendência e modos de agir, e inspiram a fuga do cotidiano, a socialização, a alegria e a afetividade, realizando-se em distintos rituais pelo Ágape. Elas permitem 
explorar, criar e dar forma à própria corporeidade. São ideias, traduzidas por uma linguagem corporal, que permitem expressar e comunicar mensagens, sensibilizando para a adoração, o belo, o estético, o cultural, o social e o espiritual. Em vez de orar com palavras, ora-se com gestos, expressando orações mediante movimentos corporais.

O carismático tem a necessidade de servir-se de seu corpo para realizar suas orações, para entrar em contato com Deus, ou para fazer com que outros se encontrem com a divindade; e todas as técnicas identificadas e aqui interpretadas têm um desses objetivos. Ousamos dizer que um carismático reza com o corpo inteiro e cada técnica do corpo tem o seu significado. O significado das técnicas corporais pode anunciar, para aqueles que as observam, a eficácia do contato com o sagrado, como uma imitação prestigiosa.

\section{Referências}

CARDOSO DE OLIVEIRA, Roberto. O trabalho do antropólogo. Campinas: Editora da UNESP; Brasília: Paralelo 15, 1998.

CSORDAS, Thomas. Corpo, significado e cura. Porto Alegre: UFRGS, 2008.

ELIAS, Norbert. Os estabelecidos e os outsiders: sociologia das relações de poder a partir de uma pequena comunidade. Rio de Janeiro: Zahar, 2000.

GEERTZ, Clifford. A interpretação das culturas. Rio de Janeiro: LCT, 1989.

GOFFMAN, Evring. A representação do eu na vida cotidiana. Petrópolis: Vozes, 2002.

MAUÉS, Raymundo H. Algumas técnicas corporais na renovação carismática católica. Ciências sociais e religião, Porto Alegre, v. 2, n. 2, p. 401-421, set. 2000.

MAUSS, Marcel. As técnicas corporais. In: . Sociologia e antropologia. São Paulo: EPU/Edusp, 2003. p. 399-422.

MENDES, Maria Isabel Brandão de Souza; NÓBREGA, Terezinha Petrucia. Cultura de movimento: reflexões a partir da relação entre corpo, natureza e cultura. Pensar a Prática, Goiânia, v. $12, \quad$ n. 2 , p. 1-10, maio/ago. 2009. Disponível em: <https://www.revistas.ufg.br/fef/article/view/6135/5361>. Acesso em: 15 maio 2017.

PABLO. Pablo (nome fictício usado na pesquisa). depoimento [fev. 2015]. Entrevistadora: L. Silva. Goiânia: Paróquia Sagrada Família, 2015. Gravação sonora digital.

PEIRANO, Marisa. Temas ou Teorias? O estatuto das noções de ritual e de performance. Caderno Campos. v. 7, n. 2, p. 9-16, abr./jun. 2006.

PEREIRA, Edilson. O espírito da oração ou como carismáticos entram em contato com Deus. Religião e Sociedade, Rio de Janeiro, v. 29, n. 2, p. 58-81, jul./dez. 2009. Disponível em: <http://www.scielo.br/pdf/rs/v29n2/v29n2a04.pdf>. Acesso em: 21 fev. 2014.

QUADROS, Elton Moreira. Eros, filia and agape: the love from the greek world to Christian conception. Acta scientiarim: human and social sciences, Maringá, v. 33, n. 2, p. 165-171, 
jul./dez.

2011.

Disponível

em:

$<$ http://www.doaaj.org/doaj?currentYear=2013\&id=1161192\&go=1\&func=abstract\&fromYe ar=\&toYear=>. Acesso em: $01 \mathrm{dez} .2013$.

RENOVAÇÃO CARISMÁTICA CATÓLICA BRASIL. A história da RCC: história mundial da RCC. s/d. Disponível em: <http://www.rccbrasil.com.br/interna.php?paginas=42>. Acesso em: 13 mar. 2015.

SILVA, Ana Márcia; LAZZAROTTI FILHO, Ari; ANTUNES, Priscilla de Césaro. Práticas corporais. In: GONZÁLEZ, Fernando Jaime; FENSTERSEIFER, Paulo Evaldo (Org.). Dicionário crítico de educação física. 3. ed. Ijuí: Unijuí, 2014. p. 522-528.

SOFIATI, Flávio Munhoz. Elementos sócio-históricos da renovação carismática católica. Estudos de religião, v. 23, n. 37, p. 216-241, jul./dez., 2009. Disponível em: <https://www.metodista.br/revistas/revistas-ims/index.php/ER/article/viewFile/1528/1554>. Acesso em: 30 mar. 2014.

\section{Agradecimentos}

O presente trabalho é fruto do mestrado acadêmico financiado pela Coordenação de Aperfeiçoamento de Pessoal de Nível Superior - CAPES. Foi apresentado no Third ISA Forum - Forum da Associação Internacional de Sociologia, realizado em julho de 2016, em Viena/Áustria. Para a apresentação, contamos com apoio financeiro da Fundação de Empreendimentos Científicos e Tecnológico - FINATEC e da Fundação Universidade de Brasília - FUB. Às instituições, nossos agradecimentos.

Recebido em: 31/08/2017

Revisado em: 11/04/2018

Aprovado em: 24/07/2018

Endereço para correspondência:

leticia.rts@gmail.com

Letícia Rodrigues Teixeira e Silva

Universidade de Brasília

Faculdade De Educação Física

Asa Norte, Brasília - DF, 70910-900 